CARTA AL EDITOR

Rev Chil Salud Pública 2020,

Vol 24(2) 166-166

\section{REFORZAR EL ACCESO A LA SALUD EN EL CONTEXTO DE COVID-19 EN MIGRANTES RECIÉN LLEGADOS A CHILE}

REINFORCING ACCESS TO HEALTHCARE IN THE CONTEXT OF COVID-19 FOR MIGRANTS WHO RECENTLY ARRIVED TO CHILE

Señor Editor,

La pandemia de la COVID-19 ha evidenciado en Chile desigualdades estructurales en lo que concierne los principales determinantes sociales de la salud, las medidas de prevención y las condiciones en las cuales se hace frente a la enfermedad. Entre estas condiciones está el acceso a servicios y previsión de salud, en el contexto de un sistema de salud segmentado como el de Chile.

Llama la atención el caso de los migrantes internacionales en nuestro país, quienes experimentan diferentes niveles de rezago en ese ámbito, reflejado, por ejemplo, en un $17 \%$ que reporta no tener previsión de salud según datos de la encuesta CASEN 20171. Esto sucede a pesar de contar con el Decreto Supremo №67 de 2016, que garantiza cobertura en el tramo A de FONASA a los migrantes sin importar su situación migratoria. Según un estudio inédito llevado a cabo en abril de este año con poblaciones migrantes internacionales de todo el país $(n=1690)$ se observó que, de aquellos migrantes que llevaban un año o menos en Chile $(n=341)$, el $44 \%$ reportaba no tener ninguna previsión de salud. Asimismo, el 38\% no sabía donde acudir en caso de tener alguna inquietud relacionada con la COVID-19². Estos resultados sugieren la importancia que el tiempo de permanencia en el país tiene para el acceso a salud en esta población, en especial el primer año de estadía.

Esta variable, junto a otras variables críticas de protección social como estatus migratorio, situación laboral y nivel socioeconómico, requiere de mayor consideración en las diversas estrategias y acciones que se desarrollan en Chile y el mundo en contextos de crisis sanitarias. Esto significaría, en Chile, garantizar la cobertura de salud de manera igualitaria a través de la implementación efectiva del Decreto Supremo №67 y reforzar la difusión de información con relevancia intercultural y lingüística. Estas son dimensiones modificables a corto plazo y que, de atenderse a tiempo, son sensibles en el acortamiento de brechas injustas y prevenibles de acceso a servicios de salud de parte de migrantes internacionales.

\title{
Agradecimientos
}

Las autoras agradecen el Servicio Jesuita a Migrantes, Comisión de Migración y Salud, el Colegio Médico de Chile, el Núcleo Milenio de Resistencia Antimicrobiana MICROB-R y la Red de investigación interdisciplinaria en enfermedades infecciosas por su participacion en el diseño y difusión del cuestionario.

Báltica Cabieses

Alice Blukacz

Programa de Estudios Sociales en Salud, Instituto de Ciencias e Innovación en Medicina, Facultad de Medicina Clínica Alemana, Universidad del Desarrollo. aclblukacz@gmail.com

\section{REFERENCIAS BIBLIOGRÁFICAS}

1. Cabieses B, Oyarte M. Health access to immigrants: identifying gaps for social protection in health. Rev Saúde Pública. 2020;54:20.

2. Cabieses B. Encuesta sobre COVID-19 a poblaciones migrantes internacionales en Chile: informe final de resultados [en línea]; 2020 [consultado en septiembre de 2020]. Disponible en: https://repositorio.udd.cl/handle/11447/3267 